\title{
METHOD FOR THE ACCELERATED TESTING OF THE DURABILITY OF A CONSTRUCTION BINDER USING THE ARRHENIUS APPROACH
}

Marcela FRIDRICHOVÁ ${ }^{1}$, Karel DVOŘÁK ${ }^{1 *}$, Dominik GAZDIČ ${ }^{1}$

\begin{abstract}
The single most reliable indicator of a material's durability is its performance in long-term tests, which cannot always be carried out due to a limited time budget. The second option is to perform some kind of accelerated durability tests. The aim of the work described in this article was to develop a method for the accelerated durability testing of binders. It was decided that the Arrhenius equation approach and the theory of chemical reaction kinetics would be applied in this case. The degradation process has been simplified to a single quantifiable parameter, which became compressive strength. A model hydraulic binder based on fluidised bed combustion ash (FBC ash) was chosen as the test subject for the development of the method. The model binder and its hydration products were tested by high-temperature $X$-ray diffraction analysis. The main hydration product of this binder was ettringite. Due to the thermodynamic instability of this mineral, it was possible to verify the proposed method via long term testing. In order to accelerate the chemical reactions in the binder, four combinations of two temperatures $\left(65\right.$ and $\left.85^{\circ} \mathrm{C}\right)$ and two different relative humidities (14 and 100\%) were used. The upper temperature limit was chosen because of the results of the high-temperature $x$-ray testing of the ettringite's decomposition. The calculation formulae for the accelerated durability tests were derived on the basis of data regarding the decrease in compressive strength under the conditions imposed by the four above-mentioned combinations. The mineralogical composition of the binder after degradation was also described. The final degradation product was gypsum under dry conditions and monosulphate under wet conditions. The validity of the method and formula was subsequently verified by means of long-term testing. A very good correspondence between the calculated and real values was achieved. The deviation of these values did not exceed $5 \%$. The designed and verified method does not also consider the influence of other effects, for instance, chemical corrosion or corrosion caused by frost-thaw cycles. However, this method could be a supplementary tool applicable to the study of degradation processes and the estimation of a binder's durability as well.
\end{abstract}

\section{Address}

1 Faculty of Civil Engineering, Brno University of Technology, Brno, Czech Republic

* Corresponding author: dvorak.k@fce.vutbr.cz

\section{Key words}

- Arrhenius approach,

- Accelerated testing,

- Durability,

- Hydraulic binders,

- Hydration. 


\section{INTRODUCTION}

Just as in other technical fields, civil engineering has seen increases in the development of new technologies, machinery and building materials. As far as materials are concerned, it is necessary to ascertain whether newly developed materials will function and perform to the required standard for the whole of their estimated life cycle. In other words, it is necessary to determine their durability. In this respect, the most reliable indicator of a material's durability is its performance in long-term durability tests; however, it may often not be possible to carry out such tests due to insufficient time. For this reason, accelerated durability tests are used, although they have the significant disadvantage of insufficient reliability. In order to improve them as much as possible, the data from experiments must be supported by formulae derived from theoretical fields, specifically the area of general physical chemistry known as reaction kinetics. A rather widespread approach uses the Arrhenius equation in modelling processes in which the temperature has an important influence (Kjellsen and Detwiler, 1992; D'Aloia and Chanvillard, 2002; Kishi and Maekawa, 1995; Lin and Meyer, 2009; Schindler, 2004). The Arrhenius equation was first used by Svante Arrhenius in his study of electrolyte dissociation (Arrhenius, 1889); however, it is widely used today as a tool for describing phenomena other than the influence of temperature on the rate of chemical reactions, e.g. diffusion, thermal and electrical conductivity, and viscosity (Han and Chaloner, 2003; Rodríguez-Aragón and López-Fidalgo, 2005; Rodríguez-Torreblanca et al. 2007).

Many authors use its various modifications for modelling, e.g., hydration processes in cement (Termkhajornkit and Barbarulo, 2012; Litherland et al. 1981). It is also used for determining the durability of plastics (Silva et al. 2014) or food (Liu et al. 2014).

The study below is concerned with a method of deriving calculation formulae for accelerated durability tests performed on a model binder and their experimental verification on a sample of a hydraulic binder model based on Fluidized Bed Combustion ash (FBC ash). The hydration process of FBC ash mixed with water can be described by two competing processes. In the early stages, the formation of ettringite occurs; subsequently, calcium hydrosilicate phases are also formed (Montagnaro, F. et al. 2007, Magrla et al. 2014). The thermodynamic stability of ettringite is low and can lead to rapid degradation of the binder (Damidot and Glasser, 1993, Zhou and Glasser, 2001).

\section{MATERIALS AND METHODS}

The basic principle of accelerated durability testing is the intentional acceleration of degradation processes.

\subsection{Materials}

A binder model based on $\mathrm{FBC}$ ash with increased $\mathrm{CaO}$ content was chosen as the subject for the experimental derivation and verification of the computational formulas. Tab 1.

The chemical composition of this model binder is described in

Tab. 1: Chemical composition of the FBC ash

\begin{tabular}{|c|c|c|c|c|c|c|c|}
\hline & $\mathrm{SiO}_{2}$ & $\mathrm{Al}_{2} \mathrm{O}_{3}$ & $\mathrm{Fe}_{2} \mathrm{O}_{3}$ & $\mathrm{SO}_{3}$ & $\mathrm{CaO}$ & $\mathrm{CO}_{2}$ & Others \\
\hline Content [\%] & 40.99 & 17.74 & 7.27 & 7.92 & 18.7 & 2.48 & 4.90 \\
\hline
\end{tabular}

The hydraulic binder model based on FBC ash was also subjected to $\mathrm{x}$-ray diffraction analysis with a Rietveld refinement (McCusker at al. 1999; Zevin and Kimmel, 1995; Scrivener et al. 2004); see Fig. 1. The hydraulic binder model exhibited a mineralogical composition usual for binders containing FBC ash. The greatest proportion of the material was made up of an amorphous aluminosilicate phase (42\%), with which a relic proportion of the original crystalline silicates was connected, i.e., quartz (13\%), feldspars (3\%) and non-decomposed clay minerals (3\%). A sign of the desulfation of any combustion gases was the presence of anhydrite (15\%) and calcium oxide (13\%), which were partly transformed into portlandite $(1.5 \%)$ and also calcite $(6 \%)$, which was produced either by carbonation or had not yet decomposed.

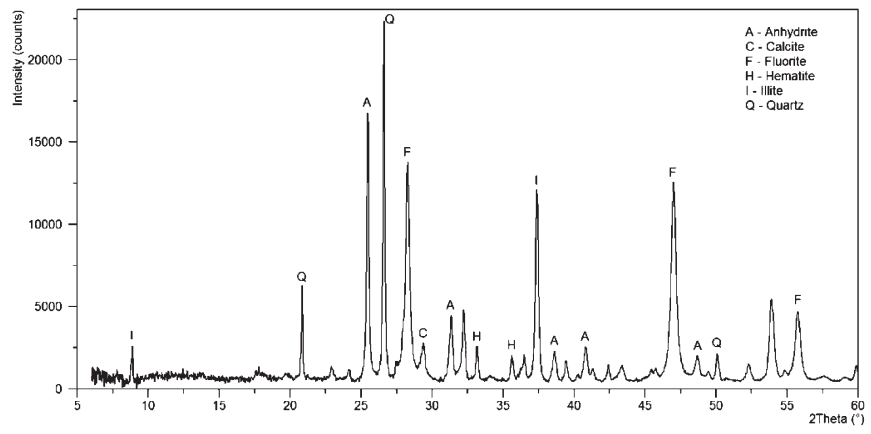

Fig. 1: XRD analysis of the hydraulic binder model prior to hydration

\subsection{Derivation of the calculation formulae}

The intentional acceleration of the degradation processes in binders can be achieved by increasing the temperature and relative humidity. Under the thus-defined degradation conditions, the following can be stated:

- first, an observed property of the material is identified, which clearly characterises the durability of the hydraulic binders; this property is compressive strength

- the durability of a hydraulic binder is defined as the time in which the strength of the cured binder drops to its so-called utility value, which is understood here as being $50 \%$ of the initial strength (i.e., its strength after 28 days of hydration under laboratory conditions)

- the cured binder specimens are exposed to at least two increased temperatures, during which their degradation progresses occur at a sufficient rate for the purposes of the experiment

- degradation due to increased temperatures takes place in at least two humidity environments, e.g., with the cured specimens in a completely dried state and in a state of full water saturation

- drawing on reaction kinetics theory and the corresponding physicochemical laws, the degradation process of hardened hydraulic binders is mathematically formulated as the dependency of the in strength at the time of storage at a given temperature and humidity.

The rate of the chemical reactions is described according to Guldberg Waag (Moore, 1972) by the general equation

$$
v=d x / d t=k^{\prime} \cdot(a-x)^{\alpha} \cdot(b-x)^{\beta} \cdot \ldots \cdot(n-x)^{v}
$$

where:

$$
\begin{array}{ll}
v=d x / d t & \text { rate of the chemical process } \\
x & \text { product concentration at general time } \mathrm{t}
\end{array}
$$

$(a-x),(b-x), \ldots(n-x)$ concentration of reactants at common time $\mathrm{t}$

$k^{\prime} \quad$ constant rate

$\alpha+\beta+\ldots v \quad$ reaction order 
whose specific form depends on the experimentally-determined reaction order (Moore, 1972).

Based on the findings of different authors (Wu et al. 1983; Roy and Idorn, 1982; Shi and Day, 1993), it can be assumed that the relation between the strength and degradation time of hardened hydraulic binders shows an exponential dependency in mathematical terms which, in terms of reaction kinetics, corresponds to a first-order reaction:

$$
-\frac{d(a-x)}{d t}=k_{1}(a-x)
$$

where:

$a \quad$ initial reactant concentration at time $\mathrm{t}=0$

$(a-x)$ initial reactant concentration at common time $\mathrm{t}=0$

k1 constant rate

and after simplification:

$$
(a-x)=a \cdot e^{-k_{1} \cdot t}
$$

Therefore, the dependence of the strength on the degradation time can be analogously concretised in equation (2) by the formula:

$$
R_{t}=R_{0} \cdot e^{-k_{1} \cdot t}
$$

where:

RO strength of the cured specimen (28 days) at degradation time $\mathrm{t}=0$

$R t \quad$ strength of the degraded specimen at degradation time $\mathrm{t}$

k1 constant rate

Equation (3) is generally valid, and its coefficients $R_{0}$ and $k_{1}$ can be formulated by statistical methods for all the specimens exposed to all the degradation environments.

The expansion of equation (3) to include the influence of the temperature can be performed using the Arrhenius equation (Arrhenius, 1889), which describes the dependency of the constant rate on the temperature,

$$
k_{1}=A^{\prime} \cdot e^{-\frac{E_{a}}{R \cdot T}}
$$

in which, in this physical-chemical process, molar activation energy can be considered a constant, and equation (4) can be simplified to:

$$
\begin{aligned}
& \text { where: } \quad k_{1}=A^{\prime} \cdot e^{-\frac{\beta}{T}} \\
& A^{\prime} \quad \text { frequency factor } \\
& E a \quad \text { molar activation energy } \\
& R \quad \text { molar gas constant } \\
& T \quad \text { Temperature } \\
& \beta \quad \mathrm{Ea} / \mathrm{R}
\end{aligned}
$$

Inserting equation (4) or (4a) into equation (3) produces a formula for the development of the strength, which is dependent on the degradation time and temperature at a constant humidity:

or

$$
R_{t}=R_{0} \cdot e^{-A^{\prime} \cdot e^{\frac{E_{a}}{R T} \cdot \tau}}
$$

$$
R_{t}=R_{0} \cdot e^{-A^{\prime} \cdot e^{-\frac{\beta}{T}} \cdot \tau}
$$

Since the durability of the hydraulic binders was declared as the time in which the strength drops to $50 \%$ of its initial value, the quotient $\mathrm{Rt} / \mathrm{R}_{0}$ achieves the value $0.5 \mathrm{R}_{0} / \mathrm{R}_{0}=0.5$. By its substitution and subsequently taking the logarithm, equation (5) takes the form:

$$
\ln 0.5=-A^{\prime} \cdot e^{-\frac{E_{a}}{R \cdot T}} \cdot \tau
$$

or

$$
\ln 0.5=-A^{\prime} \cdot e^{-\frac{\beta}{T}} \cdot \tau
$$

where:

$$
\tau \quad \text { durability }
$$

The durability of the tested binder can easily be calculated from equation (6), although it is under constant humidity but at different temperatures. If humidity is to be included in the formulae above, this variable needs to be expanded by the Arrhenius equation for the calculation of the constant rate; see equation (4). There are two coefficients in the formula to which the influence of the humidity must be related, i.e., the frequency factor A' (van't Hoff, 1884) and the molar activation energy $\mathrm{E}_{\mathrm{a}}$. Based on the mathematical analysis of the obtained data and based on an analogy with similar physical dependencies (Minaei et al. 2011; Aristov et al. 2006), it can be expected that the frequency factor $\mathrm{A}^{\prime}$ will drop exponentially according to the designed formula:

$$
A^{\prime}=A_{0}^{\prime} \cdot e^{-\alpha \cdot w}
$$

where:

$A^{\prime} \quad$ frequency factor of the system

$A 0^{\prime}$ frequency factor of the system in a dried state

$w \quad$ humidity of the system

$\alpha \quad$ humidity coefficient of the frequency factor

and the molar activation energy of the system will decrease linearly according to the designed formula

$$
E_{a}=E_{0}(1-\varepsilon \cdot w)
$$

or

$$
\beta=\beta_{0}(1-\sigma \cdot w)
$$

where:

$E_{a} \quad$ molar activation energy of the system

$E_{0} \quad$ molar activation energy of the system in a dried state

$w \quad$ humidity of the system

$\varepsilon \quad$ humidity coefficient of activation energy

$\beta_{0} \quad \mathrm{E} 0 / \mathrm{R}$

$\sigma \quad \varepsilon / \mathrm{R}$

The individual coefficients can be concretised by means of calculations from the two humidity states of the system, e.g., the dried state and the state of saturated water vapour, through the solution of the two equations of the two unknowns.

Substituting the concretised equations (7) and (8) or (8a) into equation (6) produces a complete formula for the calculation of the binder's durability with regard to its dependency on the temperature and relative humidity:

$$
\ln 0.5=-A_{0}^{\prime} \cdot e^{-\alpha \cdot w} \cdot e^{-\frac{E_{0}(1-\varepsilon \cdot w)}{R \cdot T}} \cdot \tau
$$

or

$$
\ln \frac{R_{t}}{R_{0}}=-A_{0}^{\prime} \cdot e^{-\alpha \cdot w} \cdot e^{-\frac{\beta_{0}(1-\sigma \cdot w)}{T}} \cdot \tau
$$

To allow any value of the utility strength to be entered, equation (9a) can be generalised as:

$$
\ln 0.5=-A_{0}^{\prime} \cdot e^{-\alpha \cdot w} \cdot e^{-\beta_{0}(I-\sigma \cdot w)} T \cdot \tau
$$


where:

$$
\begin{array}{ll}
R_{t} & \text { utility strength } \\
\tau & \text { durability }
\end{array}
$$

\subsection{Method and procedure of the experiment}

The binder was mixed with water and formed into specimens. After the formwork had been removed, the specimens were stored in an environment prescribed for the specific mixture for the time necessary to attain its final properties (i.e., 28 days of hydration for hydraulic binders).

The cured specimens were then analysed by XRD and stored in pre-selected degradation environments. The minimum number of degradation environments was determined by the two increased temperatures and two increased levels of humidity.

After the pre-selected time intervals, the specimens were removed from the degradation environments for determining the observed properties; in this case there was one: compressive strength. After the strength tests, the samples were subjected to XRD analysis for determining the phase composition.

The observation of the degradation must take place for at least as long as it takes to obtain a minimum number of values sufficient to smooth the functional dependence of the degradation process. Simultaneously, the chosen degradation conditions must not cause qualitative changes in the hardened mixture that are different from the changes that have occurred during the spontaneous aging. The shortterm durability tests were then evaluated according to the above-described calculation method.

\section{RESULTS AND DISCUSSION}

\subsection{Determination of the parameters of the degradation environment}

See Fig. 2 for the mineralogical composition of the hydrated model binder after 28 days.

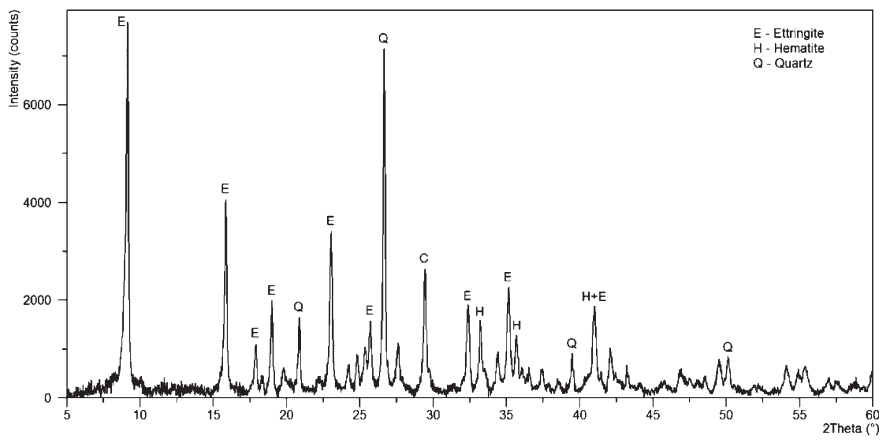

Fig. 2: XRD analysis of the model hydraulic binder after 28 days

It can therefore be stated that the hydration process of the hydraulic binder will primarily involve the formation of the primary ettringite, $3 \mathrm{CaO} \cdot \mathrm{Al}_{2} \mathrm{O}_{3} \cdot 3 \mathrm{CaSO}_{4} \cdot 32 \mathrm{H}_{2} \mathrm{O}$.

Since ettringite is thermodynamically rather unstable and especially susceptible to the action of high temperatures (Zhou and Glasser, 2001), it was necessary to subject the hardened hydraulic binder (at 28 days of hydration) to thermal x-ray diffraction analysis; see Fig. 3. The analysis has shown that the beginning of the structural decomposition of the ettringite starts to be perceptible above $85^{\circ} \mathrm{C}$, while complete decomposition occurs around $100^{\circ} \mathrm{C}$.

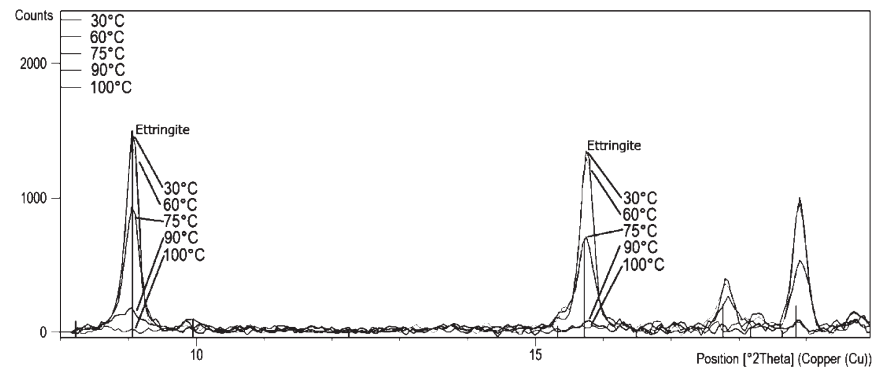

Fig. 3: Thermal x-ray diffraction analysis of the binder model after 28 days of hydration

The degradation temperatures of $65^{\circ} \mathrm{C}$ as the lower limit and $85^{\circ} \mathrm{C}$ as the upper limit were selected in order to create the best conditions for the statistical processing of the results. The aim was to achieve a sufficiently rapid degradation process, whilst respecting the specified temperature conditions for the thermodynamic stability of the ettringite.

The degradation effect of the humidity was also modelled in two variants. The first consisted of a constant relative humidity of $15 \%$ in a circulation dryer. The second operated as an environment of saturated water vapour, where the humidity reached up to $100 \%$.

Based on the thermal and humidity degradation conditions above, four degradation regimes were defined:

- $\mathbf{S 6 5}$ - temperature $65^{\circ} \mathrm{C}$, relative humidity $15 \%$

- $\mathbf{S 8 5}$ - temperature $85^{\circ} \mathrm{C}$, relative humidity $15 \%$

- M65 - temperature $65^{\circ} \mathrm{C}$, relative humidity $100 \%$

- $\mathbf{M 8 5}$ - temperature $85^{\circ} \mathrm{C}$, relative humidity $100 \%$.

A hot-air laboratory dryer with forced circulation was used for the modelling of the dry degradation environment under the specific conditions of the experiment. The beam specimens were freely laid inside it. Apart from the constant temperature, the humid environment required continuous storage in saturated water vapour. For this purpose, the beam specimens were placed above the water in polypropylene containers with perforated bottoms and sealed lids and then put in the same laboratory dryer.

\subsection{The results of the exposure of the binder to the defined environments}

First, the consistency of the binder sample was determined to be normal, according to Vicat (EN 196-3+A1:2009); its value was 0.54\%; initial setting time, $30 \mathrm{~min}$; and final setting time, 720 minutes.

Based on the normal consistency value, specimen sets were made from the pure binder paste. Each specimen set always consisted of three bars sized $20 \times 20 \times 100 \mathrm{~mm}$, and a total of 280 specimen sets were prepared.

After 24 hours of hydration, the formwork was removed from the bars, which were placed in humid storage to cure for 28 days with a stable humidity $>90 \%$ at a temperature of $21 \pm 1{ }^{\circ} \mathrm{C}$.

Prior to placing the specimens in the degradation environment, five randomly selected specimen sets were tested to determine their compressive strength at 28 days which, in the terms of the accelerated tests, effectively corresponds to strength $\mathrm{R}_{0}$. Apart from the compressive strength, the tensile strength was also determined; see Tab. 2. The compressive strength value represents the average of the six values that were measured of one set of the samples. The standard deviation did not exceed 1.5 MPa in any cases.

The cured binder specimens were divided into four groups and placed in their chosen degradation environment. The remaining five specimen sets were left in the laboratory environment for long-term 
compressive strength testing. These specimens were placed in the laboratory environment at a temperature of $22{ }^{\circ} \mathrm{C}$ and a relative humidity of $50 \%$ for 50 months.

Tab. 2: Strength of hydraulic binder model after 28 days of curing

\begin{tabular}{|l|c|c|}
\hline \multirow{2}{*}{ Set ID } & \multicolumn{2}{|c|}{ Average set strength [MPa] } \\
\cline { 2 - 3 } & Tensile & Compressive \\
\hline Set 1 & 1.06 & 24.8 \\
\hline Set 2 & 0.98 & 23.2 \\
\hline Set 3 & 1.17 & 23.4 \\
\hline Set 4 & 0.96 & 20.5 \\
\hline Set 5 & 1.10 & 22.1 \\
\hline Average & 1.05 & 22.8 \\
\hline
\end{tabular}

At least one set of specimens was removed from exposure in each of the degradation environments for the compressive strength testing. The results of the compressive strength tests for the individual degradation environments are listed in Tabs. 3 through 6.

When evaluating the phase composition of the samples by XRD after the degradation according to the selected humidity conditions, a significant difference was found between their qualitative compositions. The exposure of the samples in an environment of $15 \%$ relative humidity caused degradation of the ettringite via a gradual loss of water. In the later period, loss of hydroxyl water was observed. This resulted in the gradual decomposition of meta-ettringite into gypsum and calcium hydroaluminates (C-A-H phases).

In contrast, other ettringite samples were saturated by $\mathrm{Al}$ ions in an environment of saturated steam. This led to the transformation of the ettringite into monosulfate. The observed effects are consistent with the phenomena described in the literature (Damidot and Glasser, 1993, Zhou and Glasser, 2001).

Tab. 3: Compressive strength of the specimens exposed to degradation environment S65

\begin{tabular}{|c|c|c|c|c|c|}
\hline $\begin{array}{l}\text { Degradation time } \\
\text { [day] }\end{array}$ & $\begin{array}{c}\text { Compressive strength } \\
{[\mathrm{MPa}]}\end{array}$ & $\begin{array}{c}\text { Degradation time } \\
\text { [day] }\end{array}$ & $\begin{array}{c}\text { Compressive strength } \\
{[\mathrm{MPa}]}\end{array}$ & $\begin{array}{c}\text { Degradation time } \\
\text { [day] }\end{array}$ & $\begin{array}{c}\text { Compressive strength } \\
{[\mathrm{MPa}]}\end{array}$ \\
\hline 1 & 23.64 & 80 & 17.66 & 98 & 16.38 \\
\hline 3 & 22.33 & 82 & 16.50 & 99 & 16.25 \\
\hline 7 & 24.59 & 83 & 16.38 & 100 & 14.25 \\
\hline 14 & 23.37 & 84 & 16.67 & 103 & 15.01 \\
\hline 20 & 23.17 & 85 & 15.30 & 111 & 15.37 \\
\hline 25 & 22.08 & 88 & 16.09 & 118 & 14.37 \\
\hline 28 & 21.27 & 80 & 17.66 & 119 & 15.00 \\
\hline 35 & 19.40 & 80 & 17.66 & 122 & 14.58 \\
\hline 40 & 18.00 & 89 & 15.29 & 125 & 15.25 \\
\hline 46 & 16.86 & 90 & 14.26 & 126 & 15.00 \\
\hline 55 & 16.29 & 91 & 16.96 & 129 & 14.65 \\
\hline 74 & 16.02 & 94 & 14.73 & 132 & 15.12 \\
\hline 77 & 17.73 & 97 & 15.42 & & \\
\hline
\end{tabular}

Tab. 4: Compressive strength of the specimens exposed to degradation environment 585

\begin{tabular}{|c|c|c|c|c|c|}
\hline $\begin{array}{c}\text { Degradation time } \\
\text { [day] }\end{array}$ & $\begin{array}{c}\text { Compressive strength } \\
{[\mathrm{MPa}]}\end{array}$ & $\begin{array}{c}\text { Degradation time } \\
\text { [day] }\end{array}$ & $\begin{array}{c}\text { Compressive strength } \\
{[\mathrm{MPa}]}\end{array}$ & $\begin{array}{c}\text { Degradation time } \\
\text { [day] }\end{array}$ & $\begin{array}{c}\text { Compressive strength } \\
{[\mathrm{MPa}]}\end{array}$ \\
\hline 1 & 23.12 & 74 & 12.41 & 97 & 11.79 \\
\hline 3 & 21.96 & 80 & 11.69 & 98 & 11.17 \\
\hline 7 & 21.68 & 82 & 9.48 & 99 & 11.25 \\
\hline 14 & 19.38 & 83 & 13.22 & 100 & 8.85 \\
\hline 21 & 17.56 & 84 & 10.13 & 111 & 9.81 \\
\hline 28 & 16.32 & 85 & 12.63 & 118 & 9.55 \\
\hline 40 & 14.65 & 88 & 10.44 & 119 & 7.95 \\
\hline 46 & 14.50 & 89 & 10.71 & 122 & 9.28 \\
\hline 56 & 14.67 & 90 & 11.67 & 125 & 9.46 \\
\hline 60 & 14.17 & 91 & 11.42 & 129 & 9.50 \\
\hline 70 & 14.08 & 94 & 12.02 & 132 & 8.28 \\
\hline
\end{tabular}


Based on the above, the degradation mechanism can be explained as being due to processes taking place in the ettringite. If the crystalline pressure in the ettringite is higher than the ambient vapour pressure, an evaporation process occurs.

This process results in a gradual transformation to meta-ettringite and then in the decomposition of the amorphous phase into gypsum and $\mathrm{C}-\mathrm{A}-\mathrm{H}$ phases. In contrast, if the crystalline pressure is lower than the ambient vapour pressure, the ettringite is gradually transformed into the thermodynamically more stable monosulfate. Both these processes lead to the failure of the structure and subsequently to the degradation of the cured binder.

\subsection{Calculation of the durability of the hydraulic binder model}

\subsubsection{Concretisation of the $R 0$ and $k_{1}$ coefficients for the individual degradation environments}

The coefficients $R_{0}$ and $k_{1}$ were statistically formulated for the individual degradation environments by smoothing the strength values $R_{t}$ at the corresponding degradation time $\mathrm{t}$ with an exponential form of equation (3); see the trend line charts in Figs. 4 through 7.

Tab. 5: Compressive strength of the specimens exposed to degradation environment M65

\begin{tabular}{|c|c|c|c|c|c|}
\hline $\begin{array}{c}\text { Degradation time } \\
\text { [day] }\end{array}$ & $\begin{array}{c}\text { Compressive strength } \\
{[\mathrm{MPa}]}\end{array}$ & $\begin{array}{c}\text { Degradation time } \\
\text { [day] }\end{array}$ & $\begin{array}{c}\text { Compressive strength } \\
{[\mathrm{MPa}]}\end{array}$ & $\begin{array}{c}\text { Degradation time } \\
\text { [day] }\end{array}$ & $\begin{array}{c}\text { Compressive strength } \\
{[\mathrm{MPa}]}\end{array}$ \\
\hline 1 & 20.67 & 40 & 20.27 & 84 & 18.31 \\
\hline 3 & 22.38 & 43 & 19.19 & 92 & 17.23 \\
\hline 4 & 20.50 & 46 & 19.63 & 95 & 16.85 \\
\hline 6 & 20.00 & 55 & 18.11 & 97 & 17.12 \\
\hline 7 & 21.29 & 63 & 18.20 & 100 & 17.62 \\
\hline 12 & 17.60 & 65 & 18.13 & 112 & 16.87 \\
\hline 14 & 18.25 & 68 & 17.25 & 115 & 16.72 \\
\hline 20 & 18.30 & 72 & 17.33 & 127 & 16.82 \\
\hline 21 & 21.02 & 75 & 17.25 & 132 & 16.25 \\
\hline 30 & 20.08 & 77 & 17.42 & & \\
\hline 38 & 17.54 & 80 & 17.22 & & \\
\hline
\end{tabular}

Tab. 6: Compressive strength of the specimens exposed to degradation environment M85

\begin{tabular}{|c|c|c|c|c|c|}
\hline $\begin{array}{l}\text { Degradation time } \\
\text { [day] }\end{array}$ & $\begin{array}{c}\text { Compressive strength } \\
{[\mathrm{MPa}]}\end{array}$ & $\begin{array}{c}\text { Degradation time } \\
\text { [day] }\end{array}$ & $\begin{array}{c}\text { Compressive strength } \\
{[\mathrm{MPa}]}\end{array}$ & $\begin{array}{c}\text { Degradation time } \\
\text { [day] }\end{array}$ & $\begin{array}{c}\text { Compressive strength } \\
{[\mathrm{MPa}]}\end{array}$ \\
\hline 1 & 23.55 & 60 & 12.56 & 99 & 9.12 \\
\hline 3 & 22.03 & 65 & 13.86 & 100 & 8.90 \\
\hline 7 & 22.08 & 70 & 12.56 & 103 & 9.36 \\
\hline 14 & 19.1 & 74 & 12.42 & 111 & 8.77 \\
\hline 27 & 18.07 & 80 & 13.68 & 118 & 9.92 \\
\hline 34 & 16.65 & 82 & 11.20 & 119 & 9.67 \\
\hline 40 & 15.50 & 83 & 12.10 & 120 & 9.50 \\
\hline 42 & 12.21 & 85 & 12.13 & 121 & 7.75 \\
\hline 43 & 17.92 & 88 & 12.50 & 122 & 9.40 \\
\hline 44 & 16.33 & 89 & 9.68 & 125 & 8.90 \\
\hline 45 & 16.55 & 90 & 9.10 & 126 & 8.85 \\
\hline 46 & 13.29 & 91 & 9.67 & 129 & 8.40 \\
\hline 48 & 15.88 & 94 & 9.22 & 132 & 7.25 \\
\hline 55 & 10.88 & 98 & 9.32 & & \\
\hline 48 & 15.08 & 97 & 9.22 & & \\
\hline
\end{tabular}




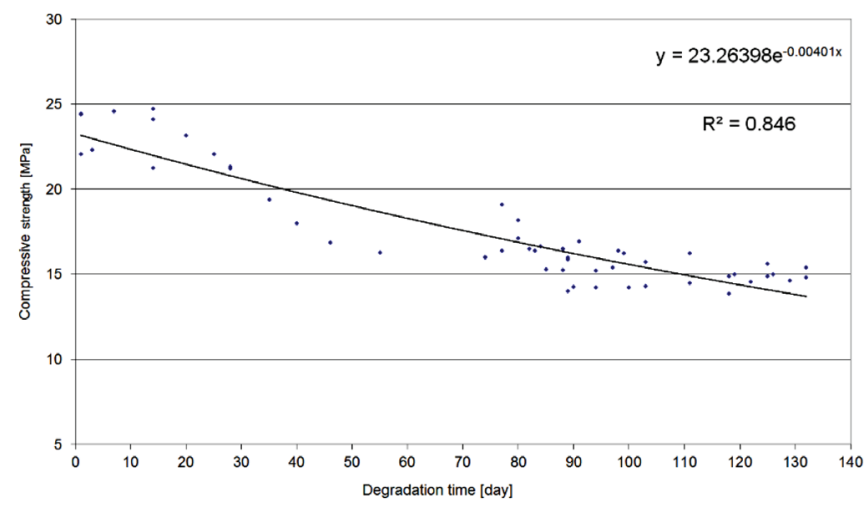

Fig. 4 Chart of the strength progression in the degradation environment $S 65$

Through the statistical formulation, the determined coefficients achieved the following values in degradation environment S65:

$R_{0}=23.264 \mathrm{MPa}$ and $k_{1}=-0.00401 \mathrm{day}^{-1}$.

Equation (3) can be concretised for the degradation environment S65 into:

$$
R_{t}=23.264 \cdot e^{-0.00401 t}
$$

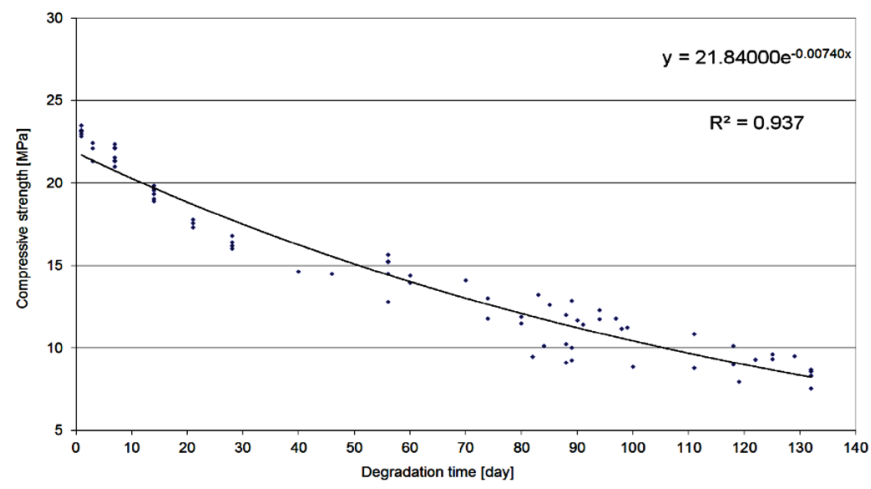

Fig. 5 Chart of the strength progression in degradation environment S85

Through the statistical formulation, the determined coefficients achieved the following values in the degradation environment S85:

$$
R_{0}=21.840 \mathrm{MPa} \text { and } k_{1}=-0.0074 \mathrm{day}^{-1} .
$$

Equation (3) can be concretised for the degradation environment S85 into:

$$
R_{t}=21.840 \cdot e^{-0.0074 t}
$$

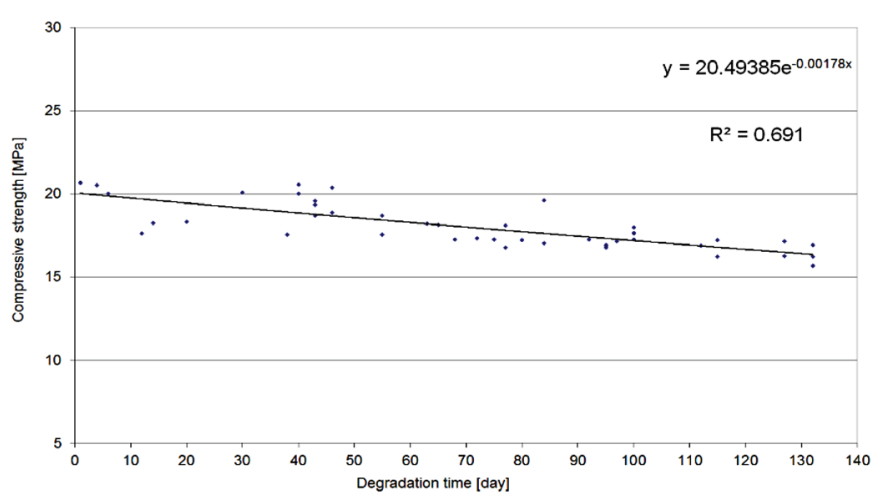

Fig. 6 Chart of the strength progression in the degradation environment M65
Through the statistical formulation, the determined coefficients achieved the following values in the degradation environment M65:

$R_{0}=20.494 \mathrm{MPa}$ and $k_{1}=-0.00178 \mathrm{day}^{-1}$.

Equation (3) can be concretised for the degradation environment M65 into:

$$
R_{t}=20.494 \cdot e^{-0.00178 t}
$$

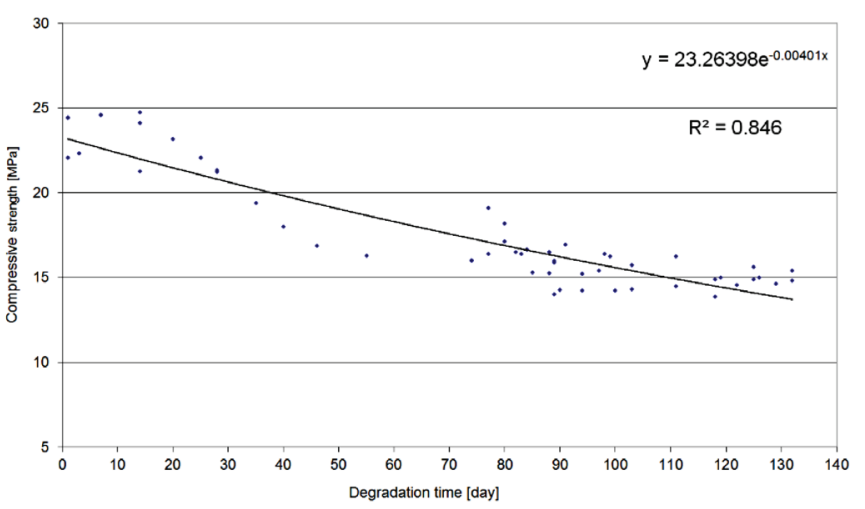

Fig. 7 Chart of the strength progression in the degradation environment M85

Through the statistical formulation, the determined coefficients achieved the following values in degradation environment M85:

$R_{0}=21.942 \mathrm{MPa}$ and $k_{1}=-0.00790 \mathrm{day}^{-1}$.

Equation (3) can be concretised for the degradation environment M85 into:

$$
R_{t}=21.942 \cdot e^{-0.0079 t}
$$

\subsubsection{Concretisation of the $A^{\prime}$ and $\beta$ coefficients for the individual humidity environments}

The concretisation was performed by substituting the concretised values of $R_{0}$ and $k_{1}$ into equation (4a) and subsequently calculating the coefficients $A^{\prime}$ and $\beta$ by solving the two equations with the two unknowns:

a) concretisation of coefficients $A^{\prime}$ and $\beta$ for the humidity environment $w=15 \%$.

$$
\begin{aligned}
& 0.0041=A^{\prime} \cdot e^{-\beta / 338} \\
& 0.0074=A^{\prime} \cdot e^{-\beta / 338}
\end{aligned} \longrightarrow \begin{aligned}
& \beta=3710.088 \\
& A^{\prime}=233.4014 \text { day }^{-1}
\end{aligned}
$$

Equation (4a) can be concretised for the humidity environment $\mathrm{w}=15 \%$ as:

$$
k_{1}=233.4014 \cdot e^{-\frac{3710.088}{T}}
$$

b) concretisation of the coefficients $A^{\prime}$ and $\beta$ for the humidity environment $w=100 \%$.

$$
\begin{aligned}
& 0.00178=A^{\prime} \cdot e^{-\beta / 338} \longrightarrow \quad \longrightarrow \quad \beta=9024.088 \\
& 0.0079=A^{\prime} \cdot e^{-\beta / 338} \quad A^{\prime}=6.92 .108 \text { day }^{-1}
\end{aligned}
$$

Equation (4a) can be concretised for humidity environment $\mathrm{w}=100 \%$ as:

$$
k_{1}=6.92 \cdot 10^{8} \cdot e^{-\frac{9024088}{T}}
$$




\subsubsection{Concretisation of coefficients $A_{o}^{\prime}$ and $a$}

This concretisation was performed by substituting the concretised values of the $A^{\prime}$ and humidity values $w$ into equation (7) and subsequently calculating the coefficients $A_{0}$ 'and $\alpha$ by solving the two equations with the two unknowns:
$233.4014=A_{0}^{\prime} \cdot e^{-\alpha \cdot 15}$
$\alpha=-0.1753$
$6,92 \cdot 10^{8}=A_{0}^{\prime} \cdot e^{-\alpha \cdot 100}$
$A_{0}^{\prime}=16.8249$

\subsubsection{Concretisation of coefficients $\beta_{0}$ and $\sigma$}

This concretisation was performed by substituting the concretised values of the $\beta$ and humidity values $w$ into equation (8a) and subsequently calculating the coefficients $\beta_{0}$ and $\sigma$ by solving the two equations with two unknowns:

$$
\begin{aligned}
& 3710.088=\beta_{0}(1-\varepsilon \cdot 15) \longrightarrow \\
& 9024.088=\beta_{0}(1-\varepsilon \cdot 100)
\end{aligned} \quad \begin{aligned}
& \varepsilon=-0.02255 \\
& \beta_{0}=2772.3239
\end{aligned}
$$

\subsubsection{Concretisation of the equation for the calculating durability}

By substituting the coefficients $\mathrm{A}_{0}{ }^{\prime}, \alpha, \beta_{0}$ and $\sigma$, equation (9a) achieves the specific form:

$$
\ln 0.5=-16.8249 \cdot e^{0.1753 w} \cdot e^{-\frac{27723239(1+0.02255 w)}{T}} \cdot \tau
$$

For normal environmental conditions, i.e., an ambient temperature of $22{ }^{\circ} \mathrm{C}$ and a relative humidity of $50 \%$, by substituting and calculating according to equation (17), the durability of the hydraulic binder model achieves the following values:

$$
\ln 0.5=-16.8249 \cdot e^{0.175350} \cdot e^{-\frac{27723239(1+0.0225550)}{295}} \cdot \tau
$$

$\tau=3550$ days or 9.7 years.

\subsection{Verification of the calculated durability of the hydraulic binder model by means of long-term testing}

\subsubsection{The real strength of the hydraulic binder model over a long-term exposure}

In order to verify the calculated durability of the hydraulic binder model, long-term exposure of the hardened specimens was carried out in a laboratory environment at a temperature of $22 \mathrm{C}^{\circ}$ and a relative humidity of $50 \%$. The specimens were removed after 560 and 1500 days of storage in order to determine their compressive strength; see Tab. 7.

Tab. 7 Long-term compressive strength of the hydraulic binder model

\begin{tabular}{|l|c|c|}
\hline \multirow{2}{*}{ Set ID } & \multicolumn{2}{|c|}{ Average compressive strength [MPa] } \\
\cline { 2 - 3 } & 560 days & 1500 days \\
\hline Set 1 & 19.6 & 14.8 \\
\hline Set 2 & 18.9 & 15.0 \\
\hline Set 3 & 19.8 & - \\
\hline Average & 19.4 & 14.9 \\
\hline
\end{tabular}

In order to verify the degradation process of the binder model in a laboratory environment, XRD analysis was carried out after 1500 days; see Fig. 8.

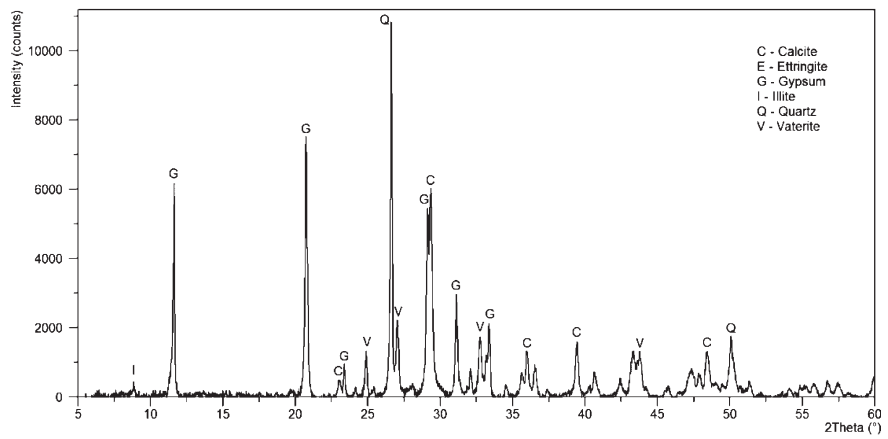
days

Fig. 8: XRD analysis of the hydraulic binder model after 1500

The crystalline pressure in the ettringite was, in this case, higher than the ambient vapour pressure. The degradation process occurred via the decomposition of the ettringite into the meta-ettringite and finally into the gypsum. It can be concluded that the degradation process in the laboratory environment was the same as in the dry model conditions.

\subsubsection{Calculation of the compressive strength of the binder at a given time of long-term exposure}

The substitution of the appropriate parameters from equation (18) into equation (10) determined the calculated strength values of the hydraulic binder at time $\tau=560$ and 1500 days, which were then compared with the values obtained through the actual testing. The value $R_{0}$ was substituted by the arithmetic average of the initial strength values determined statistically by equation (3) for all the observed environments; see equations (11) through (14), at the value 21.885 MPa.

After finding the logarithm, equation (10) took the forms:

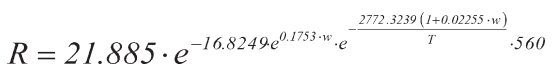

$R=19.3 \mathrm{MPa}$

and

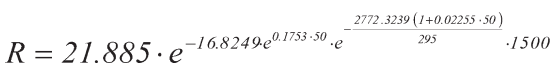

$$
R=15.7 \mathrm{MPa}
$$

In comparison with the actual value of 560-day, compressive strength at 19.4 MPa, the calculated value was $19.3 \mathrm{MPa}$. In the case of storage for 1500 days, the actual compressive strength was 14.9 $\mathrm{MPa}$, and the calculated value was $15.7 \mathrm{MPa}$. Noting that the deviation between the values being compared did not exceed $5 \%$, the correlation between the actual and calculated compressive strength values can be considered to be very close.

\section{CONCLUSION}

This article describes how a new method was developed for the accelerated testing of the durability of a construction binder, and how a computational formula for determining the durability of the building materials based on FBC ash was derived. The derivation of 
the method was performed based on the theory of reaction kinetics and follow-up analogies from general physical chemistry. The result of the degradation process was simplified to only one quantifiable parameter: compressive strength. The method is based on the assumption that the dependency of the compressive strength on the degradation time shows an exponential dependency in mathematical terms; from the perspective of reaction kinetics, it corresponds to a first-order reaction. The effect of the environment on the degradation process was formulated using the Arrhenius approach. The degradation process was achieved by increasing the temperature and relative humidity. The defined degradation conditions were chosen based on the physicochemical dependencies of the model binder. Thermodynamically unstable ettringite was identified as the main hydration product; therefore, it can be assumed that the results of the accelerated durability tests and degradation process will also be verifiable in the normal environmental conditions under which the spontaneous aging of the binder takes place. Four degradation regimes with various combinations of temperatures and relative humidity were defined for the binder. It has been found that the model binder is stable up to a temperature of $85^{\circ} \mathrm{C}$; therefore, this temperature was selected as the upper limit for the selected conditions; the lower limit was $65^{\circ} \mathrm{C}$. The degradation process also depends on the crystalline pressure in the ettringite. If the crystalline pressure in the ettringite is higher than the ambient vapour pressure, an evaporation process occurs. The ettringite transforms into meta-ettringite and then to the $\mathrm{C}-\mathrm{A}-\mathrm{H}$ phase and gypsum. In the opposite case, the end product of degradation is monosulfate. Hence, two relative humidities, namely $14 \%$ and $100 \%$, were defined as the degradation conditions. Based on the results of decreasing strength, a computational formula was derived for the model binder.

In conclusion, the durability of the binder under laboratory conditions, $22{ }^{\circ} \mathrm{C}$ and $50 \%$ R. H., was stated. The time at which the strength drops to $50 \%$ of its initial value was chosen as the criterion. Under these conditions, the calculated durability of the binder reaches 9.7 years. The validity of the method and derived calculation formula was verified using the same sample of the binder model.

The real compressive strength was determined for the binder model, whose samples were subjected to long-term (namely 560 days and 1500 days) exposure to a laboratory environment. The correlation between the calculated and real values is considered to be very close. The deviation of these values did not exceed $5 \%$. Considering the great amount of agreement between the calculated and measured compressive strength values of the specimen, it can be asserted that the designed method appears to be functional and can be used to forecast or obtain more precise durability values within technically acceptable testing times. Naturally, the choice of defined degradation conditions will always depend on the kind of binder used; hence generalization in this regard is impossible. The designed method also does not consider the influence of other effects, for instance, chemical corrosion or corrosion caused by freeze-thaw cycles. However, the method appears to be sufficient to describe the durability of binders in relatively moderate conditions. The method can also be employed as a supplementary tool in the study of degradation processes affecting building materials and to estimate the durability of binders.

\section{Acknowledgment}

This work was financially supported by Project No: 14-32942S "Effect of fluidized bed ash on the thermodynamic stability of hydraulic binders". This paper was also developed with the financial support of Project No. LO1408 „AdMaS UP - Advanced Materials, Structures and Technologies“, supported by the Czech Ministry of Education, Youth and Sports under „National Sustainability Programme I". 


\section{REFERENCES}

Kjellsen, K. O. - Detwiler, R. J., (1992) Reaction kinetics of Portland cement mortars hydrated at different temperatures, Cement and Concrete Research. Vol. 22, pp. 112-120.

D'Aloia, L. - Chanvillard G., (2002) Determining the 'apparent' activation energy of concrete: Ea-numerical simulations of the heat of hydration of cement, Cement and Concrete Research. Vol. 32, pp. 1277-1289.

Kishi, T. - Maekawa K., (1995) Multi component model for hydration heating Portland cement, Translation from Proceedings of JSCE. No. 526/V-29.

Lin, F. - Meyer, C. (2009) Hydration kinetics modeling of Portland cement considering the effects of curing temperature and applied pressure, Cement and Concrete Research. Vol. 39, No. 4, pp. $255-265$.

Schindler, A. K. (2004) Effect of temperature on the hydration of cementitious materials, ACI Materials Journal. Vol. 101, No 1, pp. $72-81$

Arrhenius, S. (1889) Ober die reacktionsgeschwindigkeit bei der inversion von rohrzucker durch saüren, Z. Physikal. Chemie. Vol. 4, pp. 226-248.

Han, C. - Chaloner, K., (2003) D- and c-optimal designs for exponential regression models used in viral dynamics and other applications, Journal of Statistical Planning and Inference. Vol. 155, pp. 585-601.

Rodríguez-Aragón, L. J. - López-Fidalgo, J. (2005) Optimal designs for the Arrhenius equation, Chemometrics and Intelligent Laboratory Systems. Vol. 77, pp. 131-138.

Rodríguez-Torreblanca, C. - Rodríguez Díaz, J.,M., (2007) Locally $D$ - and c-optimal designs for Poisson and Negative Binomial regression models, Metrika 66, pp. 161-172.

Termkhajornkit, P. - Barbarulo, R., (2012) Modeling the coupled effects of temperature and fineness of Portland cement on the hydration kinetics in cement paste, Cement and Concrete Research. Vol. 42, pp. 526-538.

Litherland, K.,L. - Oakley, D.,R. - Proctor, B.,A. (1981) The use of accelerated ageing procedures to predict the long term strength of GRC composites, Cement and Concrete Research. Vol. 11, pp. 455-466.

Silva, M. A. G. - Sena da Fonseca, B. - Biscaia, H. (2014) On estimates of durability of FRP based on accelerated tests, Composite Structures. Vol. 116, pp. 377-387.

Liu, X. - Jiang, Y. - Shen, S. - Luo, Y. - Gao, L. (2014) Comparison of Arrhenius model and artificial neuronal network for the quality prediction of rainbow trout (Oncorhynchus mykiss) fillets during storage at different temperatures, LWT - Food Science and Technology. Vol. 60, pp. 142-147.
Montagnaro, F. - Nobili, M. - Salatino, P. - Telesca, A. - Valenti, G. L., (2007) Hydration products of FBC wastes as SO2 sorbents: comparison between ettrungite and cylcium hydroxide, Fuel Processing Technology. Vol. 89, pp. 47-53.

Magrla, R. - Fridrichova, M. - Kulísek, K. - Dvořák, K. - Hoffman, O. (2014) Utilisation of Fluidised Fly Ash for Reduction of CO2 Emissions at Portland Cement Production. Advanced Materials Research. Vol. 1054, pp. 168-171.

Damidot, D. - Glasser, F. P. (1993) Thermodynamic investigation of the $\mathrm{CaO}-\mathrm{Al}_{2} \mathrm{O}_{3}-\mathrm{CaSO}_{4} \cdot \mathrm{H}_{2} \mathrm{O}$ system at $25^{\circ} \mathrm{C}$ and influence of $\mathrm{Na} \mathrm{O}_{2}$, Cement and Concrete Research. Vol. 23, pp. 221-238.

Moore, W. J., (1972) Physical Chemistry, Prentice Hall, Inc., USA.

Wu, X. - Langton, C. A. - Roy D. M. (1983) Hydration of slag cement at early stage, Cement and Concrete Research. Vol. 13, pp. $277-286$

Roy, D. M - Idorn, G. M. (1982) Hydration structure and properties of blast furnace slag cements, mortars and concrete, American, Concrete, Institute Proceedings. Vol. 79, pp. 444-457.

Shi, C. - Day, R. L. (1993) Acceleration of strength gain of lime-pozzolan cements by thermal activation, Cement and Concrete Research. Vol. 23, pp. 824-832.

van't Hoff, J. H. (1884) Études de Dynamique Chimique (Studies in Chemical Dynamics), Utrecht

Minaei, S. - Motevali, A. - Najafi, G. - Seyedi, S. R. M. (2011) Influence of drying methods on activation energy, effective moisture diffusion and drying rate of pomegranate arils, Australian Journal of Crop Science. Vol. 6, pp. 584-591.

Aristov, Y. I. - Tokarev, M. M. - Freni, A. - Glaznev, I. S. - Restuccia, G. (2006) Kinetics of water adsorption on silica Fuji Davison $R D$, Microporous and Mesoporous Materials. Vol. 96, pp. 65-71.

McCusker, L. B. - Von Dreele, R. B. - Cox, D. E. - Louër, D. Scardi, P. (1999), Rietveld refinement guidelines, Applied Crystallography. Vol. 32, pp. 36-50.

Zevin, L. S. - Kimmel, G. (1995): Quantitative X-ray Diffractometry. Publisher Springer Verlag. New York

Scrivener, K. L. et al (2004) Quantitative study of Portland cement hydration by $X$-ray diffraction/Rietveld analysis and independent methods. Cement and Concrete Research. Vol. 34, pp. 1541-1547.

Zhou, Q. - Glasser, F. P. (2001) Thermal stability and decomposition mechanisms of ettringite at $<120^{\circ} \mathrm{C}$, Cement and Concrete Research. Vol. 31, pp.1333-1339.

EN 196-3+A1:2009 Methods of testing cement - Part 3: determination of setting time and soundness 